\title{
Analysis of impact of longitudinal inclination of a chain conveyor on dynamical phenomena during operation
}

\author{
Kamil Szewerda ${ }^{2, *}$, Jerzy Świder ${ }^{1}$, and Krzysztof Herbuś ${ }^{1}$ \\ ${ }^{1}$ Institute of Engineering Processes Automation and Integrated Manufacturing Systems, Faculty of \\ Mechanical Engineering, Silesian University of Technology, ul. Konarskiego 18a, 44-100 Gliwice, \\ Poland \\ ${ }^{2}$ The Laboratory of Virtual Prototyping Methods, The Institute of Mining Technology KOMAG \\ ul. Pszczyńska 37, 44-100 Gliwice, Poland
}

\begin{abstract}
Armoured face conveyors (AFCs) of length even up to 500 meters are used in coal mines for transportation of run-of-mine. The method of their installation depends on the geological and mining conditions and on a coal seam position. Operation of AFC in a horizontal or inclined position is allowed. The maximum accepted inclination is determined by the machine manufacturer. Two directions of longitudinal inclination of the conveyor have to be considered: upward and downward transportation of excavated material. Both the angle and the direction of inclination of the conveyor have a significant impact on the dynamics of its operation. Change in inclination of AFC results in tension of the chain. Loosening the scraper chain can lead to blockage, what can be a reason of damage. Excessive chain tension results in speeding up frictional wear of conveyor components. Determination of an impact of longitudinal inclination of the conveyor on a degree and a place of loosening or excessive tension of the chain was the objective of the numerical analyses, the results of which are presented. Analysis were performed using the developed numerical model of the Rybnik 850 conveyor. These analyses are a part of the preparatory work aiming at development of the control algorithm of AFC, to prevent the formation of unfavorable dynamic effects during the conveyor operation.
\end{abstract}

\section{Introduction}

AFCs are the main machines used in longwall complexes in hard coalmines. Transportation of run-of-mine from the longwall face to beam stage loaders (BSL) and cooperation with other machines of the complex, i.e. powered roof supports and a mining machine are their main tasks. Geological conditions, including the seam position, force the required supporting system and AFC operation. AFCs can operate in horizontal position, but they can also be inclined. Inclination of AFC changes its operational dynamics. Series of tests of AFC with use of numerical simulations were carried out to identify changes in the

\footnotetext{
*Corresponding author : kszewerda@komag.eu
} 
conveyor's dynamics in the case of its longitudinal inclination. Two cases of the conveyor's longitudinal inclination were considered. The first of them is a situation, when the conveyor's return end is placed above the discharge end and run-of-mine is transported downwards. The second case is a situation, when discharge end is placed above the return end and run-of mine is transported upwards. Amount and direction of conveyor's inclination forced the method of chain load and decided about the places in which the chain was loosened or tensioned [1,2]. Results of analyses of simulation tests of the conveyor's operation under changeable angle and direction of longitudinal inclination are presented.

Such analysis is one of the phases of development of an algorithm for control of conveyors operation aiming at improvement of its operational parameters, which minimise unfavourable phenomena during transportation of run-of-mine upwards and downwards.

\section{Computational model of the conveyor}

Analysis of impact of longitudinal inclination of AFC route on dynamic phenomena that occur during its operation was made on the basis of simulation tests with use of the computational model of RYBNIK 850 conveyor with E260 conveyor's pan profile with two scraper chains of size $34 \times 126$ placed in the middle. The computational model (Fig.1) consisted of the following components: 773 rigid solids, 182 geometric nodes, 3213 defined contacts between selected rigid solids, 676 elastic-attenuating components and of two electric motors supplied from frequency transducers. The model had 1779 degrees of freedom. Numerical simulations were carried out with use of co-simulation technology, which enables integrating the software used in analyses of kinematics and dynamic of a multi-body system with Matlab $\backslash$ Simulink software, in which the electric motors were modelled [3-5].

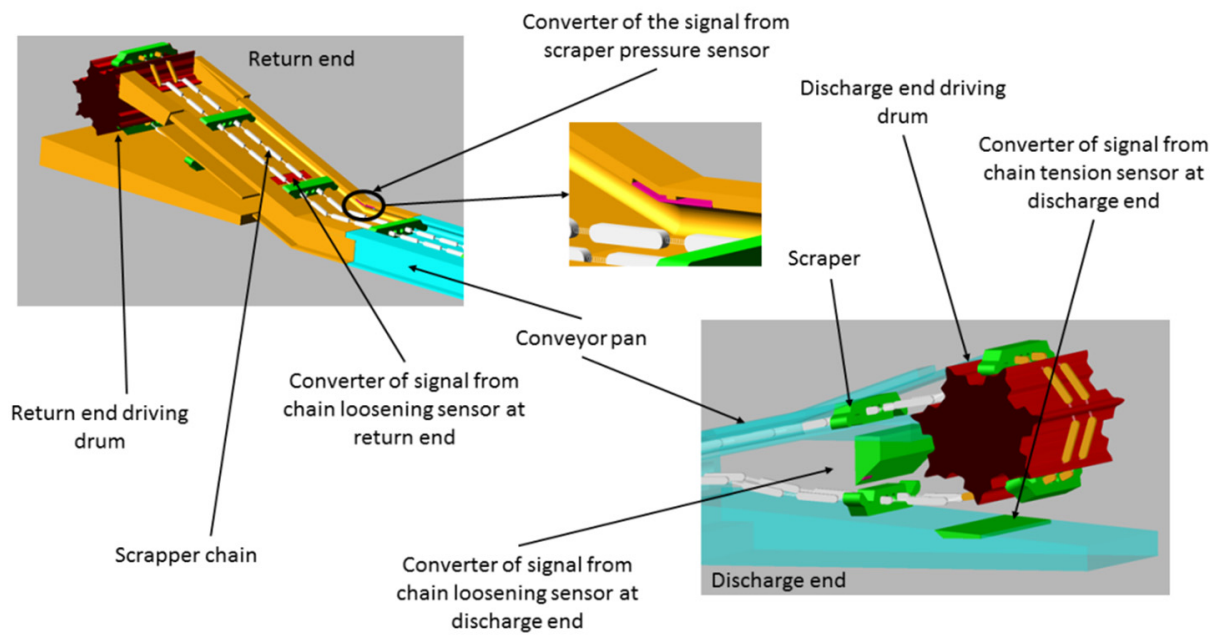

Fig. 1. Computational model of AFC [5].

Two - gear electric motors of 2SGS 400S-12/4 type manufactured by Damel S.A. were used in the computational model. The torque generated by motors was transferred to the driving drums through a gear. Vectors of load to upper line of the scraper chain, simulating the transported material, were defined. Vectors were applied to centres of solid of the selected scrapers, were attached to them and moved with them during chain motion.

Direction of load vectors was vertical. The force was defined as the parameters, so it was possible to control it during simulation. Movement resistance resulting from 
transported material on upper line of the scraper chain was recreated and controlled by the vectors $[6,7]$. The vector of acceleration of gravity $\bar{g}$ during operation of a horizontal conveyor (not inclined) was defined in the computational model. Direction of the vector action was vertical (according to $\mathrm{Y}$ axis of the global coordination system). Sense of the gravity vector was accepted towards negative values of $\mathrm{Y}$ axis and its value was equal to $9.81 \mathrm{~m} / \mathrm{s}^{2}$. The vector defined the action of the field of gravity on all solids describing the conveyor's geometry. Change in the conveyor inclination resulted in appearance of two components of the gravitation vector. Knowing the inclination angle and direction of inclination (upward, downward), it was possible to modify the gravitation vector's components. The diagram of modification of the gravitation vector according to direction and inclination of the conveyor is presented in Fig. 2.

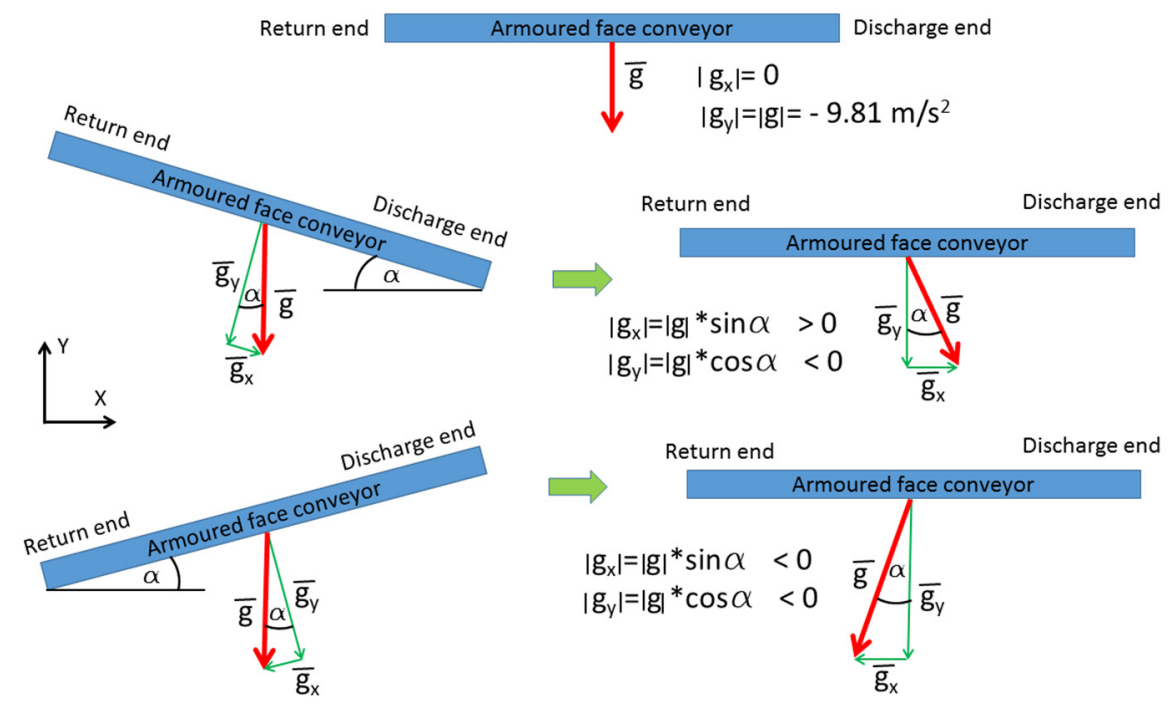

Fig. 2. Components of the vector of gravitation in the computational model [5].

Numerical simulations of operation of the inclined conveyor was possible due to implementation of the gravitation vector. A change of the inclination angle causes a change of components of the gravitation vector - the vertical component ( $\mathrm{Y}$ axis) was equal to acceleration of gravity multiplied by cosine of the inclination angle and the horizontal component ( $\mathrm{X}$ axis) was equal to acceleration of gravity multiplied by sine of the inclination angle. Direction of the conveyor inclination is described by a sense of the horizontal component of the gravitation angle. In the case of downward transportation (the discharge station situated below the conveyor's return end), the horizontal component of the gravity vector was positive. In the case of upward transportation (the discharge station situated above the conveyor's return end), the horizontal component of the gravity vector was negative.

\section{Analysis of operation of horizontal conveyors and those inclined upwards or downwards}

Simulations of conveyor operation were carried out at the following boundary conditions:

-Electric motors were supplied through frequency transducers (frequency $50 \mathrm{~Hz}$ ).

-The conveyor had a constant length. 
- At $7^{\text {th }}$ second of simulation, two vectors recreating the load to the upper line of the scraper chain with the transported material were activated. The force pressing the scraper to the conveyor pan was $200 \mathrm{kN}$.

To analyse the impact of longitudinal inclination of a conveyor's route on the phenomena occurring during its operation, first simulation of the operation of the not inclined conveyor was made and then operation of the conveyor of longitudinal inclination equal to $10^{\circ}, 20^{\circ}$ and $30^{\circ}$ was simulated and analysed, both in the case of upward and downward transportation. Current of electric motors and tension of the chain at the place of leaving the driving drums were recorded during simulation.

In Table 1, minimal, maximal and average current in the motor, recorded during simulation of stable operation with the load to the upper chain line at different longitudinal inclinations is given.

Table 1. Current in electric motors during stable operation of the conveyor with load [5].

\begin{tabular}{|c|c|c|c|c|c|c|}
\hline Inclination & $\begin{array}{c}\text { Min. } \\
\text { current at } \\
\text { discharge } \\
{[\mathrm{A}]}\end{array}$ & $\begin{array}{c}\text { Max. } \\
\text { current at } \\
\text { discharge } \\
{[\mathrm{A}]}\end{array}$ & $\begin{array}{c}\text { Average } \\
\text { current at } \\
\text { discharge } \\
{[\mathrm{A}]}\end{array}$ & $\begin{array}{c}\text { Min. } \\
\text { current } \\
\text { at return } \\
\text { end [A] }\end{array}$ & $\begin{array}{c}\text { Max. } \\
\text { current } \\
\text { at return } \\
\text { end [A] }\end{array}$ & $\begin{array}{c}\text { Average } \\
\text { current at } \\
\text { return end } \\
{[\mathrm{A}]}\end{array}$ \\
\hline \multicolumn{7}{|c|}{ Stable operation with load } \\
\hline Downward $30^{\circ}$ & 129.9 & 179.8 & 139.4 & 124.7 & 168 & 136.7 \\
\hline Downward $20^{\circ}$ & 134.2 & 144.9 & 139.3 & 127.1 & 148.3 & 136.8 \\
\hline Downward $10^{\circ}$ & 136.7 & 142.9 & 139.8 & 131.4 & 145.7 & 137.5 \\
\hline No inclination & $\mathbf{1 3 3 . 5}$ & $\mathbf{1 4 9 . 3}$ & $\mathbf{1 4 0 . 6}$ & $\mathbf{1 3 5 . 7}$ & $\mathbf{1 4 4 . 5}$ & $\mathbf{1 4 0 . 4}$ \\
\hline Upward $10^{\circ}$ & 138.7 & 154.4 & 145.3 & 136.8 & 151.8 & 144.2 \\
\hline Upward $20^{\circ}$ & 119.2 & 188.9 & 144.3 & 137.9 & 151.1 & 143.8 \\
\hline Upward $30^{\circ}$ & 98.5 & 262.8 & 147.4 & 138 & 175.3 & 147.3 \\
\hline
\end{tabular}

In the same way the results of simulations regarding other phases of the conveyor operation i.e. stable operation without the load, start-up phase and the uneven load to the conveyor were collected. After analysis it was found that:

-regarding the conveyor operation on inclination, the amplitude between minimum and maximum current in electric motors increases in comparison with horizontal operation, what is especially visible in transportation of run-of-mine upwards with inclination $20^{\circ}$ and $30^{\circ}$

-there is a significant increase of dynamics of the electric motor at the discharge end during transportation of run-of-mine with high inclination; loosening the chain observed in the case of stable operation, without the load to the upper line of the chain in its upper line during leaving the driving drum at the return end, causes high oscillations of current in the motor at the discharge end

-at the moment of applying the load to the upper line of the chain, the current increases in near the same way, when the conveyor is moving horizontally or transporting run-of-mine up at high inclination $\left(30^{\circ}\right)$; in the case of transportation of run-of-mine downward at high inclination, current of the electric motor at the discharge end increased more gently than in the case, when the conveyor was not inclined; and in the case of the motor at return end, current at the moment of applying the load to the upper line of the chain increased faster, when the conveyor operated downwardly than in the case of the not inclined conveyor, what results from the fact that a sliding force of transported material reduces movement resistance that has to be overcome by the electric motor at the discharge end. More rapid increase of current in a the motor at the return end at the moment of loading the upper chain in the case of the inclined conveyor resulted in necessity of overcoming the component force of chain gravity. 
Together with a change of longitudinal inclination and its direction, tension of the chain and a place of the chain loosening change as well. Chain tension was recorded by the sensors installed in the computational model $[5,7]$. The sensors enabled detecting the chain loosening, when leaving the driving drum both at the discharge and return ends as well as detecting the excessive chain tension at the discharge end. Besides, the pressing force of scrapers on the conveyor's pan surface at the return end was also measured. Loosening of the chain, what is disadvantageous regarding the conveyor's operational dynamics, as well as possibilities of a scraper jamming or loose chain link leading to a chain break, were identified. Excessive chain tension, which negatively affects the conveyor operation, speeding up frictional wear of conveyor's subassemblies and causing heat emission around the machine, was also measured. In Table 2 chain tensions recorded during numerical simulations of conveyor operation at different longitudinal inclinations are given. In the third column of Table 2, values of signals from the sensor about chain condition, recorded during simulation are presented. In the case of chain loosening and chain tension sensors at discharge end the signals have value 0 or 1 , what means that the given state is present or not. For the sensor of the scraper's pressing force on the conveyor's pan surface, range of its values recorded during simulations are given.

Table 2. Chain tension at the selected angle and direction of the conveyor inclination [5].

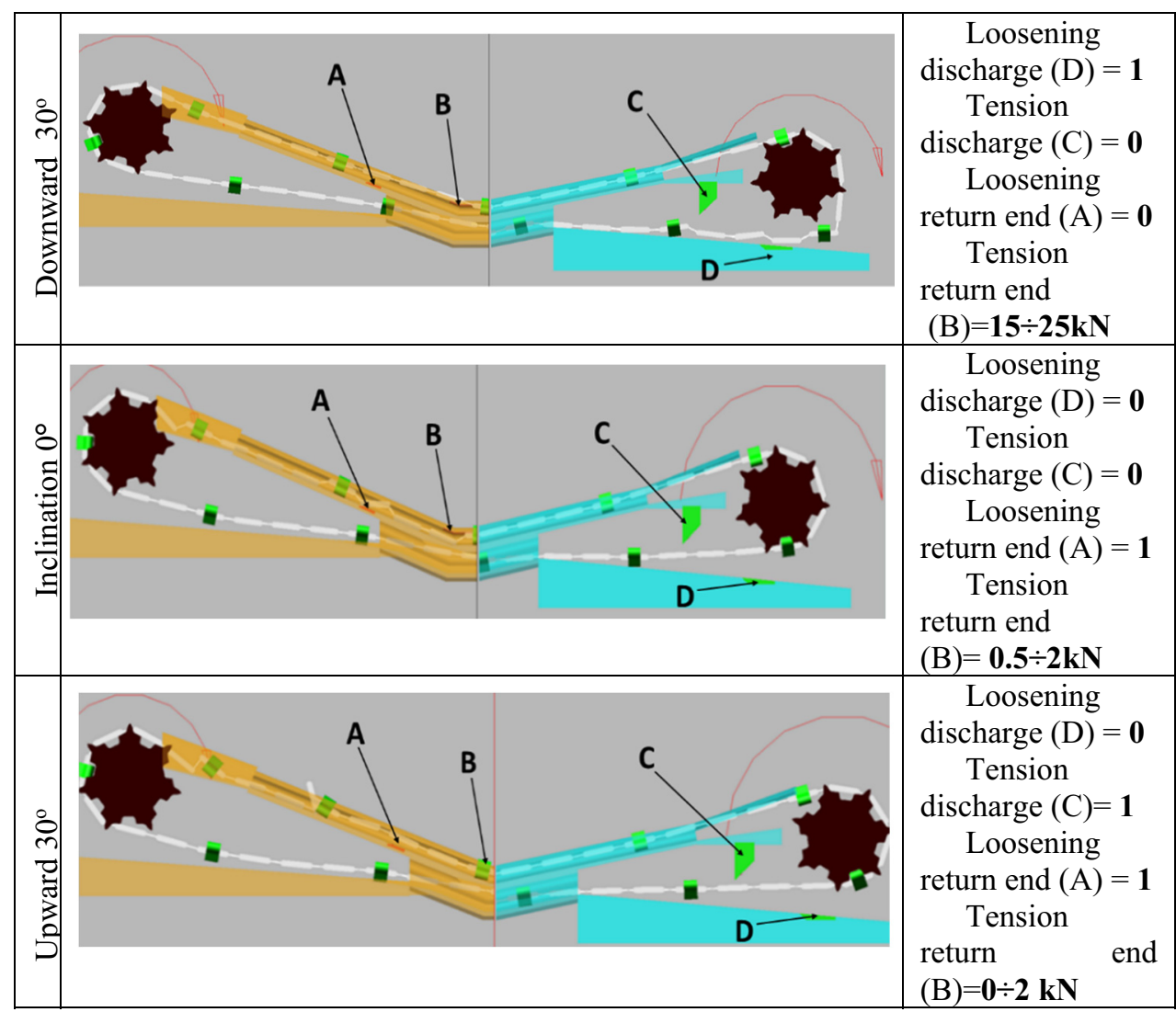

During operation of the conveyor in downward inclination, the chain was loosened at leaving the driving drum located at the discharge end. With an increase of the downward inclination angle, chain tension at leaving the driving drum located at the return end increased (there was a high pressing force of the scraper on the pan surface and on the 
sensor recording that pressure). At inclinations $20^{\circ}$ and $30^{\circ}$, the chain loosening sensor at the return end reached a value " 0 ". In this case chain tension was high. At inclination $10^{\circ}$ signal recorded by the loosening sensor at the return end reached a value " 1 ", what meant that scrapers were in a position within the sensor's range of detection. At the same time, the signal from chain tension sensor at the return end informed about occurrence of the small pressing force of the scraper, so in this situation the chain tensioning condition at leaving the driving drum at return was interpreted as the proper one (the chain was tensioned enough to avoid its loosening and jamming the scraper, without excessive pressure on the conveyor's pan).

During operation of the not inclined conveyor, there was neither excessive chain tension nor its loosening at leaving the discharge end. Such chain condition was advantageous. At this chain condition, minimal, periodical slight chain loosening, when leaving the driving drum at the return end, was observed.

At the other side, during upward operation of the conveyor, the chain was loosened, when leaving the driving drum at the return end (Fig. 3). In addition, chain tension was recorded, when leaving the driving drum at the discharge end. Significant loosening of the chain, when leaving the driving drum at the return end led to dangerous scraper blockade, causing high dynamic overloads and even to chain break.
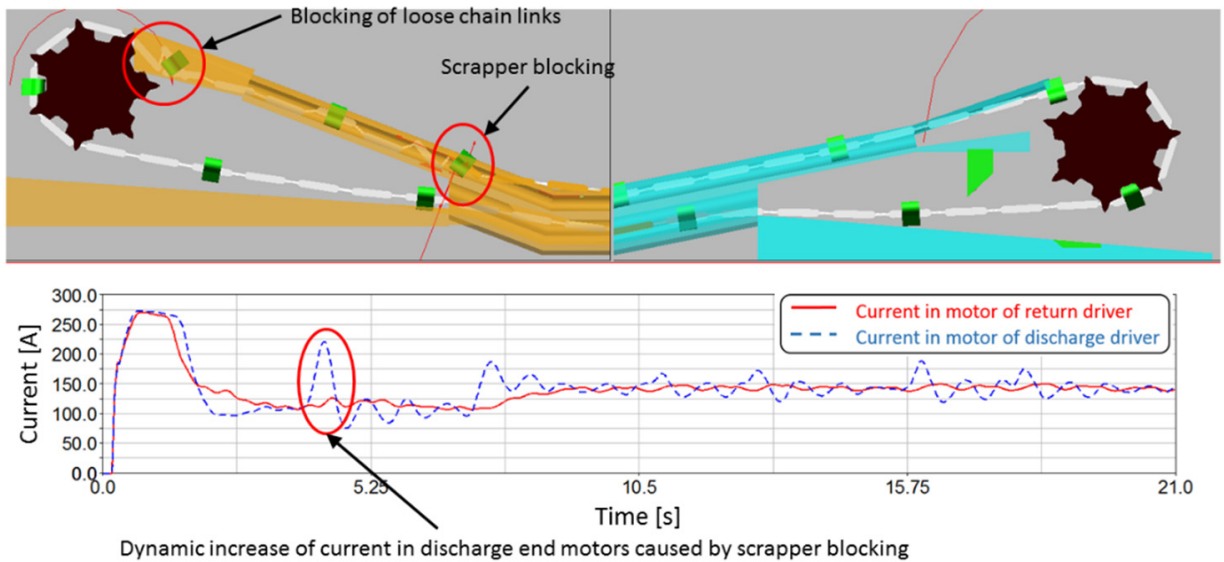

Fig. 3. Results of chain loosening at the conveyor's return end [5].

Rapid increase of current in the motor at the discharge end in the result of scrapers blockade at the return end was observed during operation of the conveyor inclined upwardly under angle $20^{\circ}$, at $4^{\text {th }}$ second of simulation (Fig. 3).

\section{Conclusions}

During conveyor operation, its driving motors generate the torque, which is multiplied and transferred to driving drums. Cooperation of driving drums with a chain results in a transformation of torque into the pulling force moving the chain with scrapers and transported run-of-mine. Resistance of conveyor movement and the transported materials has to be overcome to maintain constant transportation speed. During correct operation of the conveyor, the sum of torques generated by motors is proportional to movement resistance. Basing on numerical analyses we can say that change in a longitudinal inclination results in change of movement resistances of the upper and bottom chain. The changes result mainly from action of the sliding force generated by mass of conveyor 
components and transported run-of-mine. The sliding force increases with increase of the conveyor inclination angle. Depending on a direction of inclination, the force differently affects the load to the conveyor. During downward transportation, the rolling force reduces movement resistance in the upper chain. In turn, pulling the bottom part of the chain up causes increased movement resistance of the bottom chain. The reverse situation is during transportation of run-of-mine in the upward direction.

Differentiation in movement resistance of the upper and bottom part of the chain causes significant difference in loads to the conveyor's chain. These differences result in a chain loosening at different places of the conveyor. During upward transportation, the chain loosens, when leaving the driving drum at the return end. During downward transportation, the chain loosens, when leaving the driving drum at the discharge end. Increase of conveyor's longitudinal inclination in downward operation causes increase of the scrapers pressing force on the conveyor pan at the return end. That results in an increase of movement resistance, temperature as well as speeded up frictional wear of conveyor components.

Change in longitudinal inclination of the conveyor does not result in significant increase of the load to the driving motors, but causes big differences in chain tensions at the return end and the discharge end. Excessive tension and loosening of the chain are very disadvantageous regarding the dynamics of conveyor's operation and they may lead to failure or damage to the conveyor.

Results of analyses justify taking into account the conveyor's longitudinal inclination in a control system to minimise the risk of failure.

The article is a result of the project realized within doctoral grant financed by KOMAG Institute of Mining Technology. Calculations were made on the computers of Centrum Informatyczne Trójmiejskiej Akademickiej Sieci Komputerowej (Academic Computer Center in Gdansk -TASK).

\section{References}

1. J. Antoniak, Improvement of operational parameters of run-of-mine transportation to increase coal production from longwall panels. Kierunki Mechanizacji Górnictwa do 2010 roku. KOMTECH 2002 (Komdruk-Komag, Gliwice, 2002)

2. M. Dolipski, The dynamics of the chain conveyors (Silesian University of Technology, Gliwice, 1997)

3. K. Herbuś P. Ociepka, IOP Conf. Series: Materials Science and Engineering 95012084 (2015)

4. K. Herbuś, G. Kost, D. Reclik, J. Świder, Advanced Materials Research 837, 582-587 (2014)

5. K. Szewerda: Method of parametrization and selection of algorithms for AFC's control. KOMAG Institute of Mining Technology (to be published)

6. J. Świder, K. Herbuś, K. Szewerda, J. Achiev. Mater. Manuf. Eng. 73/2, 165 - 175 (2015)

7. K. Herbuś, K. Szewerda, J. Świder, Model. Inż. 55, 34-41 (2015) 